\title{
UNUSUAL ENTEROBIUS-HOOKWORM CO-INFECTION PRESENTING WITH SEVERE ANAEMIA IN AN APPARENTLY IMMUNOCOMPETENT PATIENT: A CASE REPORT
}

\author{
Isra Halim1, Vinaya Shetty2, Nidhish Kumar³, Vinay Khanna ${ }^{4}$ \\ ${ }_{1}^{1}$ Postgraduate Student, Department of Microbiology, Kasturba Medical College, Manipal. \\ 2Postgraduate Student, Department of Microbiology, Kasturba Medical College, Manipal. \\ ${ }^{3}$ Postgraduate Student, Department of Pathology, Kasturba Medical College, Mangalore. \\ ${ }^{4}$ Associate Professor, Department of Microbiology, Kasturba Medical College, Manipal.
}

\begin{abstract}
Helminthic infections as a major cause for morbidity in the third world are not unknown. Because of limited medical access, coinfections of parasites in patients, especially from the lower socioeconomic strata is more often a norm than sporadic. Hookworm infections have frequently been reported along with other helminths and protozoans. Surprisingly, however, hookworm-pinworm co-infections have seldom if ever been reported. The implications of this dual infection in terms of intestinal microbial antagonism or synergy, prevalence, natural history of the disease and therapeutic options is therefore uncharted territory in the vast expanse of Intestinal Parasitic Infections (IPI). We discuss here a case of an immuno-competent adult male harbouring this unusual co-infection, questioning innumerable intestinal immune mechanisms that check such infections.
\end{abstract}

\section{KEYWORDS}

Dual Infection, Hookworm, Enterobius vermicularis.

HOW TO CITE THIS ARTICLE: Halim I, Shetty V, Kumar N, et al. Unusual enterobius-hookworm co-infection presenting with severe anaemia in an apparently immunocompetent patient: a case report. J. Evolution Med. Dent. Sci. 2016;5(72):5322-5323, DOI: $10.14260 /$ jemds/2016/1205

\section{INTRODUCTION}

Intestinal Parasitic Infections (IPI) are accountable for considerable morbidity in a vast majority of the population, particularly in developing countries. ${ }^{1}$ Pathological parasitic infections often lead to malnutrition, anaemia, cognitive impairment and increased susceptibility to other infections. . $^{2,3}$ Low socioeconomic status, poor hygiene, paucity of potable water, low literacy rates, large family size and poor health status of the host are significant risk factors contributing to these infections. ${ }^{1,2,3}$ Almost a quarter of the world's population is infected with intestinal parasites causing morbidity, which almost certainly represents just the tip of the iceberg. ${ }^{4}$ Globally, 740 million people have been reported to be infected with hookworm and another 300 million with Enterobius vermicularis.5,6

Parasitic co-infections are not a rarity, especially in populations with limited medical access. Numerous studies have established the dramatic effects of co-infections in susceptible populations, such as retro-positive patients. ${ }^{7}$ Furthermore, many cases with co-infections of multiple species of helminths have been reported in medical literature. ${ }^{8}$ However, hookworm-pinworm co-infection in an immunocompetent host has rarely if ever been reported. Parasitic co-infections cannot be overlooked and demand detailed investigations, since they may alter both treatment and susceptibility to infections. ${ }^{9,10}$ Here, we present a rare case of a hookworm-pinworm co-infection from a tertiary care teaching hospital in South India.

Financial or Other, Competing Interest: None.

Submission 31-07-2016, Peer Review 24-08-2016,

Acceptance 30-08-2016, Published 08-09-2016.

Corresponding Author:

Dr. Isra Halim,

\#298, Patliputra Colony,

Patna-800013.

E-mail: israhalim@gmail.com

DOI: $10.14260 /$ jemds $/ 2016 / 1205$

(c) $(7)$

\section{CASE REPORT}

A 60 year old male patient, from a lower socioeconomic background was admitted to the medicine ward of Kasturba Hospital, Manipal, South India with presenting concerns of easy fatigability and diarrhoea since 15 days. The patient had no history of fever, abdominal pain, vomiting or tenesmus. There were no similar complaints in other members of the family. A thorough clinical examination revealed pallor, but no other significant findings. Routine investigations confirmed the same with haemoglobin levels of $5.1 \mathrm{gm} / \mathrm{dL}$ indicative of severe anaemia.

The patient's stool sample was sent for evaluation to the Division of Parasitology, Department of Microbiology, Manipal. Macroscopically, the stool was semi-formed with a blackish discolouration. The sample was examined for occult blood, which was negative. On parasitological examination, eggs of Enterobius vermicularis and Ancylostoma duodenale were obtained along with adult forms of the same. A repeat stool sample and an early morning perianal swab confirmed our initial findings. An upper gastrointestinal scopy simultaneously revealed a solitary antral nodule. The reports were conveyed to the Department of Medicine, following which the patient was started on Tab. Albendazole. In view of severe anaemia, 2 units of whole blood were also transfused.

On subsequent examination, the patient showed significant clinical improvement. Haemoglobin levels rose to $8.9 \mathrm{gm} / \mathrm{dL}$. The patient was discharged after detailed counselling for maintaining proper standards in hygiene and sanitation and advised to come for regular follow-up to the OPD.

\section{DISCUSSION}

Dual infections cannot be ignored in a developing country like ours with an increasing rural to urban migration of population. A thorough review of available literature reveals different rates of dual helminthic infections throughout the country. A study in Puducherry, South India to estimate the prevalence of helminthic infections among school children found that dual infections accounted for $8.40 \%$ of all parasitic infections. ${ }^{11}$ 
Parameshwarappa KD et al reported a rate of $19.9 \%$ for the same. ${ }^{12}$

Hookworm co-infections with other helminths and protozoans have been reported in the past. A combination of Ascaris lumbricoides and hookworm had the highest prevalence $(2.96 \%)$ followed by hookworm and Taenia spp. $(1.48 \%)$ in a recent study by Ragunathan et al11 Other researchers have reported similar results with their experience in dual parasitic infestations. ${ }^{13,14}$ However, a coinfection of hookworm with Enterobius vermicularis has not been published so far in medical literature to the best of our knowledge.

Seldom reported we have yet to decipher the implications of such co-infections in immunocompetent hosts, especially in the context of natural history of the disease and therapeutic options. Although albendazole or mebendazole have been the mainstay of therapy against hookworm since times long past, a study by Blackwell et al concluded that antiprotozoal agents may provide short-term benefits, but do not appear to have lasting effects due to constant reinfection. ${ }^{15}$ An effective treatment for either parasite is not likely without a coalition of short-term therapy and long-term improvements in sanitation systems and access to clean drinking water besides health awareness amongst the masses.

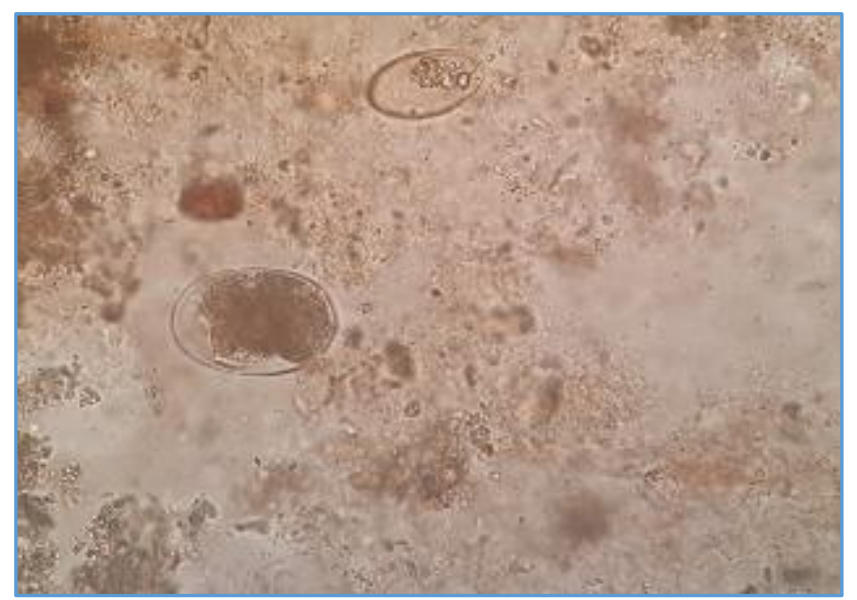

Fig. 1: Egg of Hookworm (below) with Thin Hyaline Shell and Blastomeres (60 $\times 36 \mu \mathrm{m})$ and Planoconvex Egg of Enterobius Vermicularis (55 $\times 30 \mu \mathrm{m}$ ) (above) seen on Iodine Wet Mount Preparation (40X)

\section{CONCLUSION}

The focus of most parasitic co-infections has been centred mainly on immunologically challenged and paediatric populations. Little has been spoken about these infections in apparently immunocompetent adult hosts. Pathogenic mechanisms of the establishment of these infections in a hostile intestinal niche and their consequences are yet to be clearly elucidated. Co-infections with multiple parasites cannot be overlooked clinically or diagnostically. The need of the hour is also to target appropriate public health measures and awareness, to where they are yet to see the light of the day, viz. rural regions of the developing world.

\section{REFERENCES}

1. Tinuade O, John 0, Saheed O, et al. Parasitic aetiology of childhood diarrhea. Ind J Paediatr 2006;73(12):1081-4.

2. Quihui L, Valencia ME, Crompton DWT, et al. Role of the employment status and education of mothers in the prevalence of intestinal parasitic infections in Mexican rural school children. BMC Pub Health 2006;6:225-32.

3. Östan I, Kilimcioglu AA, Girginkardesler N, et al. Health inequities: lower socio-economic conditions and higher incidences of intestinal parasites. BMC Pub Health 2007;7:342-50.

4. Kang G, Methew MS, Rajan DP, et al. Prevalence of intestinal parasites in rural Southern Indians. Tropical Med International Health 1998;3(1):70-5.

5. Fauci A, Braunwald E, Kasper D, et al. Intestinal nematodes. Chap 210. In: Harrison's principles of internal medicine. 17th edn. McGraw-Hill 2008.

6. De Silva NR, Brooker S, Hotez PJ, et al. Soil transmitted helminth infections: updating the global picture. Trends Parasitol 2003;19(12):547-51.

7. Huckans MS, Blackwell AD, Harms TA, et al. Integrated hepatitis $\mathrm{C}$ virus treatment: addressing comorbid substance use disorders and HIV infection. AIDS 2005;19(Suppl 3):S106-15.

8. Lello J, Knopp S, Mohammed KA, et al. The relative contribution of co-infection to focal infection risk in children. Proc Biol Sci 2013;280(1754):20122813.

9. Telfer S, Lambin X, Birtles R, et al. Species interactions in a parasite community drive infection risk in a wildlife population. Science 2010;330(6001):243-6.

10. Labeaud AD, Malhotra I, King MJ, et al. Do antenatal parasite infections devalue childhood vaccination? PLoS Negl Trop Dis 2009;3(5):e442.

11. Ragunathan L, Kalivaradhan SK, Ramadass S, et al. Helminthic infections in school children in Puducherry, South India. J Microbiol Immunol Infect 2010;43(3): 228-32.

12. Parameshwarappa KD, Chandrakanth C, Sunil B. The prevalence of intestinal parasitic infestations and the evaluation of different concentration techniques of the stool examination. Journal of Diagnostic and Clinical Research 2012;6(7):1188-91.

13. Phathammavong O, Moazzam A, Xaysomphoo D, et al. Parasitic infestation and nutritional status among schoolchildren in Vientiane, Lao PDR. J Paediatr Child Health 2007;43(10):689-94.

14. Celik T, Daldal N, Karaman U, et al. Incidence of intestinal parasites among primary school children in Malatya. Turkiye Parazitol Derg 2006;30(1):35-8.

15. Blackwell AD, Martin M, Kaplan H, et al. Antagonism between two intestinal parasites in humans: the importance of co-infection for infection risk and recovery dynamics. Proc Biol Sci 2013;280(1769):20131671. 